\title{
Design and production of toilet seat lifting mechanism
}

\author{
Tsui-Er Lee ${ }^{1, a}$, Rong-Mao Lee ${ }^{2}$ and Pao-Ting Liu ${ }^{2}$ \\ ${ }^{1}$ Asia University, Office of Physical Education, 41354 Taichung City, Taiwan \\ ${ }^{2}$ National Chin-Yi University of Technology, Department of Mechanical Engineering, 41170 Taichung City, Taiwan
}

\begin{abstract}
Different physiological structure between genders reflects on daily life, in which "going to toilet" is mostly concerned. Going to toilet is an important triviality every day but is closely related to personal health. Since toilet seats directly contact with the skin, the cleanness presents critical influence on physiological health and psychological comfort. It is common to share a set of sanitary equipment in the family, where females reveal several times higher probability on contacting with toilet seats. Aiming at home toilet seats being easily polluted, an improvement program is proposed in this study to reduce gender conflict with a simple mechanism design, which is improved through experiments. Keywords: female population advantage, toilet seat, female right, convenient design of toilet, use efficiency of toilet.
\end{abstract}

\section{Motivation and purpose}

Female population (11.684133 million) in Taiwan for the first time exceeded male population (11.683187 million) by November, 2013 [1]. The problem of gender rights has become more important following the advance of society and gender equality issues. Current research on gender difference and gender conflict focuses more on public places. However, different physiological structure between genders inducing daily convenience conflict and health problems has the trivial "going to toilet" be often concerned. According to the report of Taiwan Health Foundation [2], females in Taiwan appear 8 times higher probability than males suffering from urinary tract inflammation. The factor in such a big difference could be found from male and female physiological structure. The upper part of urinary tract for both genders is the same, i.e. similar length from kidney, ureter to bladder, while the lower part of urinary tract (urethra) appears obvious difference, i.e. males about $10 \sim 12 \mathrm{~cm}$ and females merely $3 \sim 4 \mathrm{~cm}$. Once the environment is not clean or the urination habit is not good, bacteria could easily invade and induce female urinary tract infection. For this reason, maintaining the cleanness of toilet seats is critical. The simple toilet seat lifting could easily induce conflict, and males and females often disagree with each other on who should lift the seats [3]. Females therefore have to suffer from health risks caused by dirty seats. Aiming at home toilet seats, an easy engineering improvement is proposed in this study. Focusing on "plug-in installation and simple operation", the engineering design is expected to create the femalefriendly home sanitary environment.

\section{Design of seat lifting mechanism}

The device is a pure mechanism design, which is operated manually without consuming electricity. The design follows the following requirements.

* Simple mechanism operation.

* Being able to solve gender conflict in toilet.

* Being able to improve toilet cleanness. (Adjusting the standing position of male urination.)

* Not inducing new problems.

* Easy production and assembly.

The mechanism operation process is shown in Figure 1. Both toilet seat lifting and rebound require buffer to avoid damage and noise.

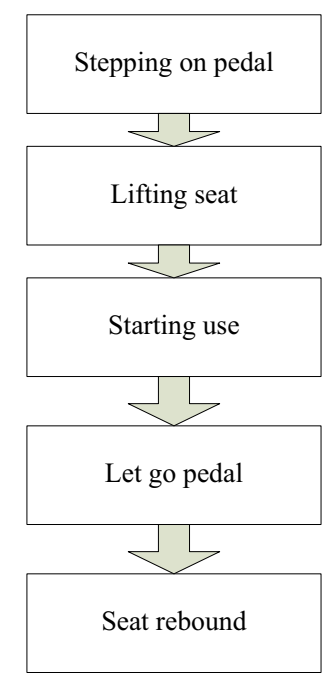

Figure 1. Seat lifting mechanism operation process.

\footnotetext{
${ }^{\mathrm{a}}$ Corresponding author: vivian@asia.edu.tw
} 


\subsection{Mechanism component}

Figure 2 and Figure 3 demonstrate the mechanism, which is expected to contain the elements of seat lifting bar, fixing bar, pedal, and damper. The fixing bar connects the toilet seat base, providing the mechanism fixing force. The pedal presents the functions of (1)leading males standing on the proper position to maintain the toilet cleanness (close to the toilet and aiming at the toilet center) and (2)driving the seat lifting bar to lift the toilet seat upwards and backwards. In order to have the toilet seat automatically "cover" the toilet, after use, by gravity (for the consideration for females), the lifting range appears in $75^{\circ} \sim 85^{\circ}$. Finally, the toilet seat up and down would induce noise and even result in damage to the toilet body or the seat. A buffer damper is therefore equipped so as to slowly decline the toilet seat after males going to the toilet to control the noise and reduce damage.

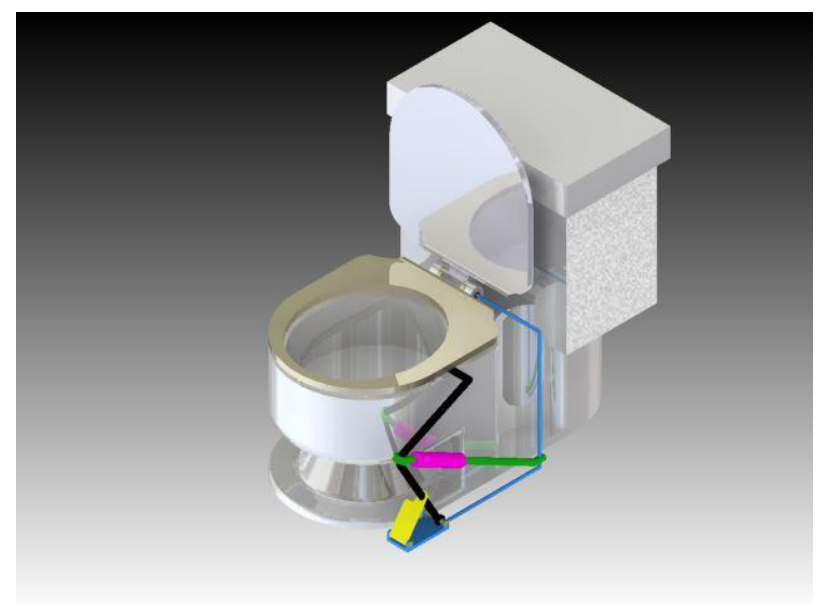

Figure 2. Demonstration of toilet seat lifting mechanism. (static)

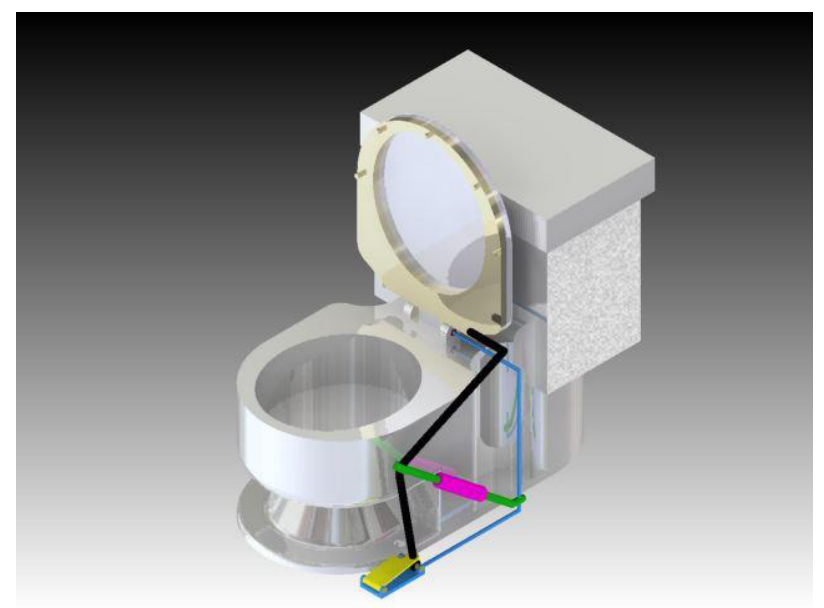

Figure 3. Demonstration of toilet seat lifting mechanism. (lifted)

\subsection{Design of mechanism size}

Because of distinct toilet specifications and patterns as well as sole sizes, the following items need to be calculated with statistics in order to determine the size and specifications of various mechanism parts.

\subsubsection{Common toilet size}

The toilet geometric shape and the sizes of various parts would affect the mechanism bar length design. The statistical survey of toilet hardware could enhance the universality of seat lifting mechanism. As HCG toilet shows the highest market share in Taiwan [5], the specification is used as the reference of the basic design (Figure 4 [4]). From Figure 2, the toilet height is important for the seat lifting mechanism size design. The common toilet height is about $360 \sim 400 \mathrm{~mm}$ [6], and the height of $385 \mathrm{~mm}$ reveals the highest repetition. The mechanism proposed in this study therefore is based on the height of $385 \mathrm{~mm}$ and offers certain range of adjustable height.

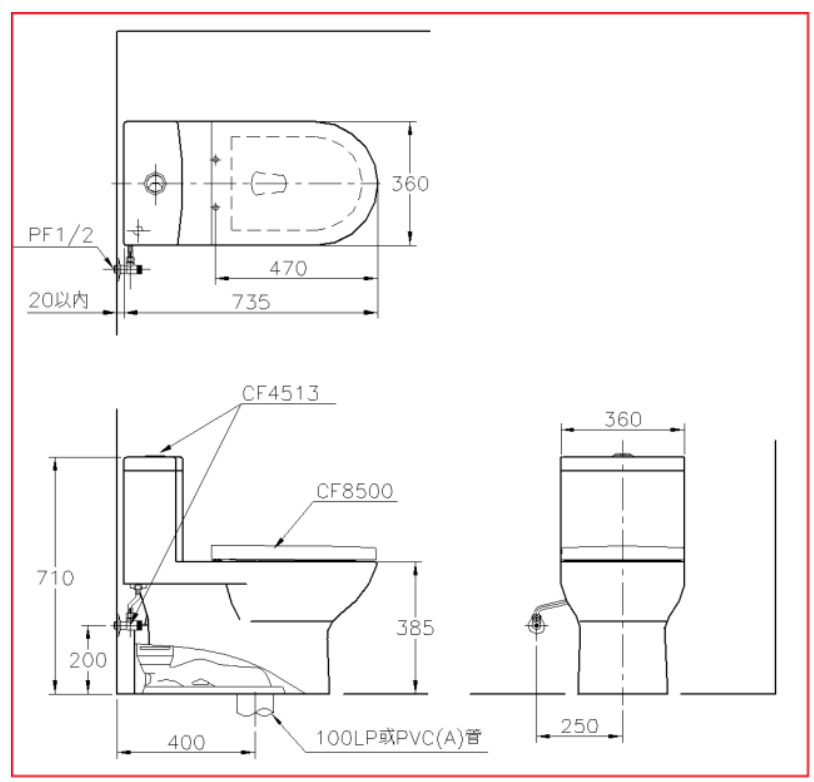

Figure 4. Demonstration of toilet specification [4].

\subsubsection{Pedal width and length}

The mechanism design aims to allow males conveniently maintaining the toilet cleanness (related to female health) without "bending down to lift the seat". For convenient operation, the average length of the maximum left foot and right foot shapes of domestic males [7] is applied to the standard pedal length (Table 1 and Table 2).

Table 1. Average left sole length of domestic males [7]. (cm)

\begin{tabular}{|c|c|c|c|c|c|}
\hline $\begin{array}{c}\text { Age } \backslash \\
\text { Region }\end{array}$ & $\begin{array}{c}\text { Northern } \\
\text { Taiwan }\end{array}$ & $\begin{array}{c}\text { Middle } \\
\text { Taiwan }\end{array}$ & $\begin{array}{c}\text { Southern } \\
\text { Taiwan }\end{array}$ & $\begin{array}{c}\text { East } \\
\text { Taiwan }\end{array}$ & Total \\
\hline $18-50$ & 24.3544 & 24.244 & 23.8063 & 27.8186 & 24.294 \\
\hline $51-60$ & 27.9 & 23.621 & 28 & - & 23.862 \\
\hline $61-70$ & - & 26.154 & 29.74 & - & 26.552 \\
\hline $71 \sim$ & - & 25.7767 & - & - & 25.7767 \\
\hline Total & 24.3837 & 24.2411 & 24.1228 & 27.8186 & 24.311 \\
\hline
\end{tabular}


Table 2. Average right sole length of domestic males [7]. (cm)

\begin{tabular}{|c|c|c|c|c|c|}
\hline $\begin{array}{c}\text { Age } \backslash \\
\text { Region }\end{array}$ & $\begin{array}{c}\text { Northern } \\
\text { Taiwan }\end{array}$ & $\begin{array}{c}\text { Middle } \\
\text { Taiwan }\end{array}$ & $\begin{array}{c}\text { Southern } \\
\text { Taiwan }\end{array}$ & $\begin{array}{c}\text { East } \\
\text { Taiwan }\end{array}$ & Total \\
\hline $18-50$ & 22.7686 & 21.803 & 23.4663 & 25.62 & 22.186 \\
\hline $51-60$ & 24.2 & 20.54 & 21.4 & - & 20.67 \\
\hline $61-70$ & - & 22.661 & 23.44 & - & 22.197 \\
\hline $71 \sim$ & - & 20.5433 & - & - & 20.5433 \\
\hline Total & 22.7804 & 21.7015 & 23.4009 & 25.62 & 22.0869 \\
\hline
\end{tabular}

\subsection{Mechanism design program}

According to above requirements and statistics, four types of seat lifting structure are designed the operation functions.

\subsubsection{Mechanism A}

Following the demonstrated structure (Figure 2), the fixing bar is integrated with the rebound device, Figure 5.
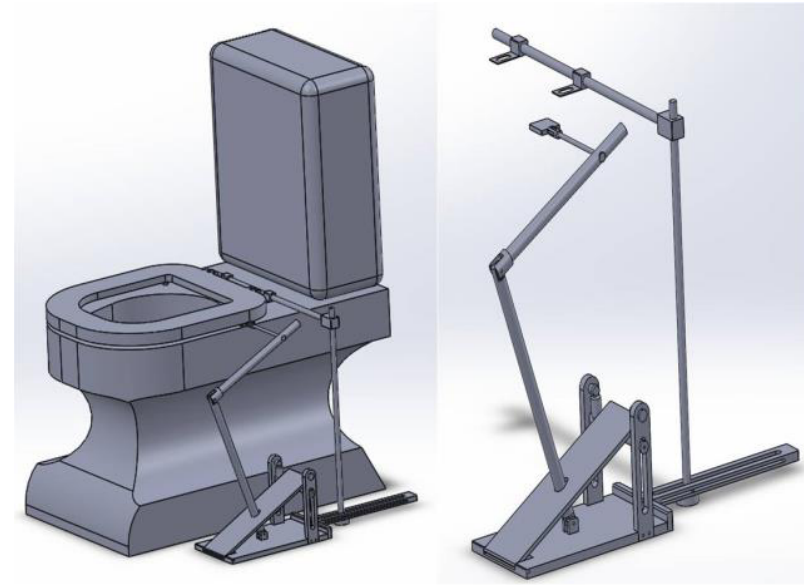

Figure 5. Mechanism A

\subsubsection{Mechanism B}

The pedal and bars in Mechanism A are easily stocked because of dead center that the contact point is changed into the sliding runner structure (Figure 6).

\subsubsection{Mechanism C}

In consideration of the pedal stock in Mechanism A, a toggle mechanism [8], Figure 7, is applied to design Mechanism $\mathrm{C}$, in addition to the sliding runner structure in Mechanism B, Figure 8.

\subsubsection{Mechanism D}

In spite that both Mechanism B and Mechanism C allow smoothly lifting seats, the seat lifting range of such two mechanisms cannot achieve the requirement $\left(75^{\circ} \sim 85^{\circ}\right)$. Referring to the idea of trash can lid lifting mechanism (Figure 9 [5]), the functional improvement is proceeded in mechanism D, Figure 10, in order to enhance the seat lifting range.

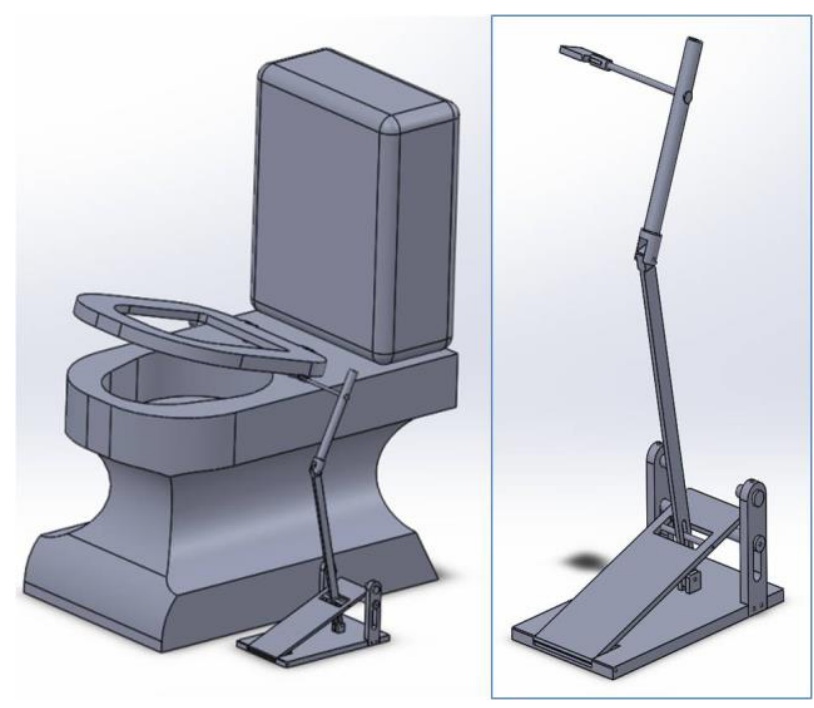

Figure 6. Mechanism B

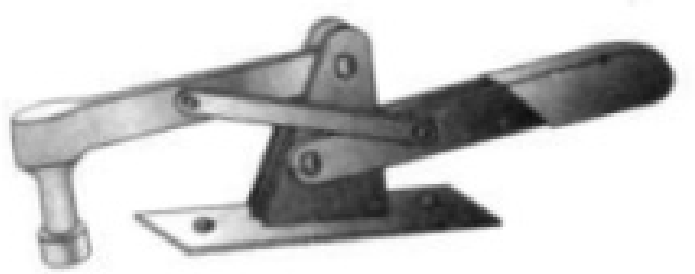

Figure 7. Toggle mechanism [8].
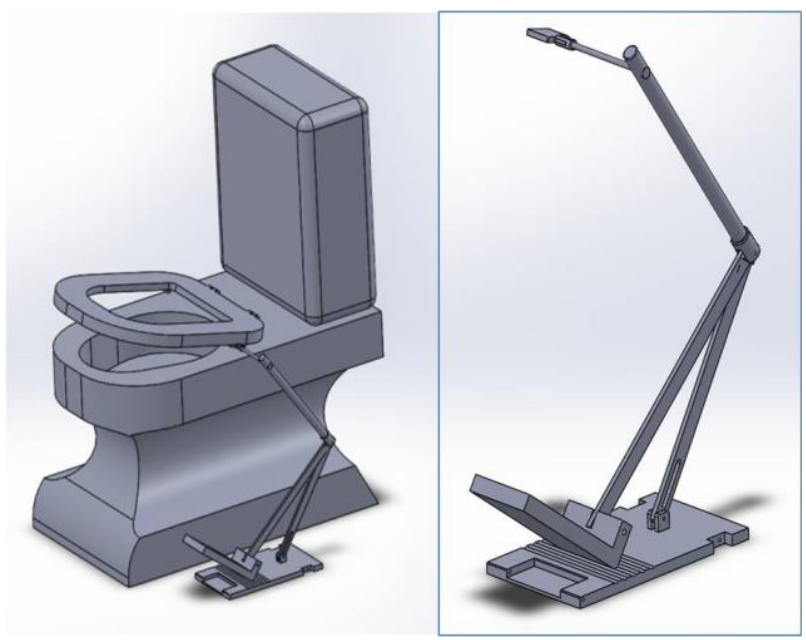

Figure 8. Mechanism C 

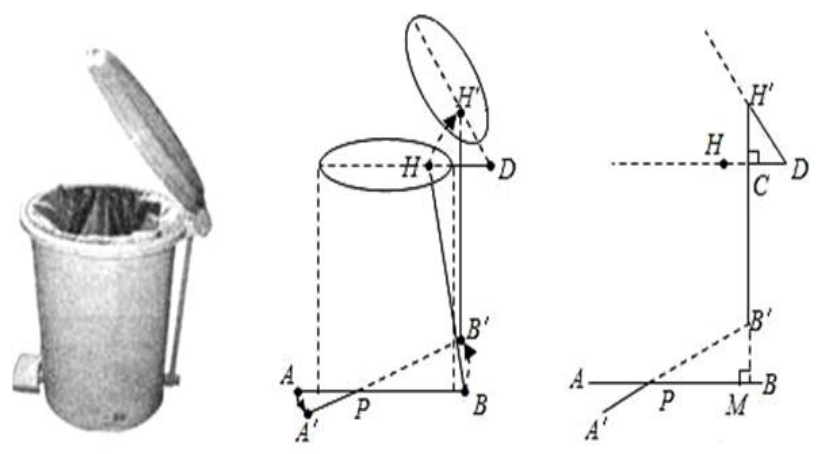

Figure 9. Trash can mechanism [5]
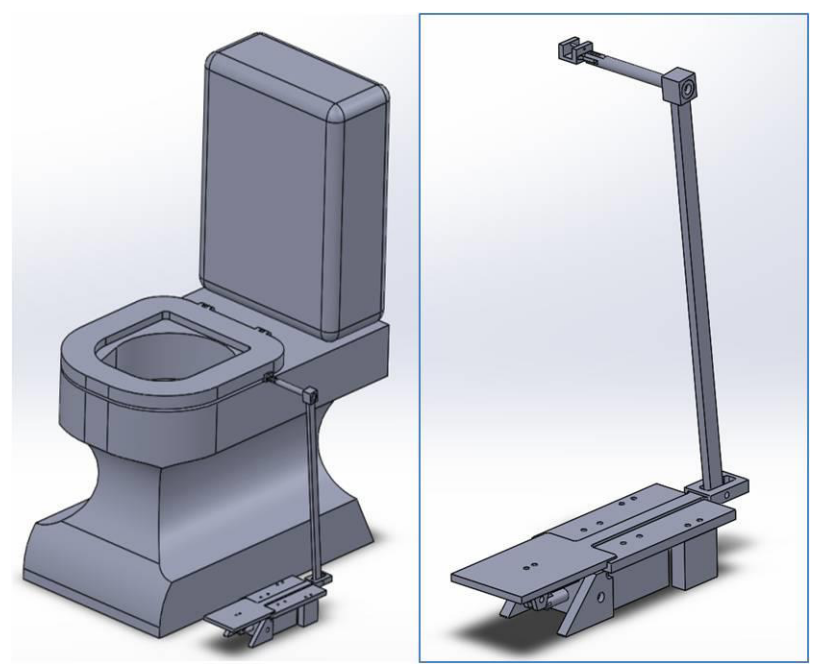

Figure 10. Mechanism D

Table 3 shows the comparison among four types of mechanism design; and, the simulation with Solidworks Motion presents that merely Mechanism D could completely lift toilet seats to $75^{\circ} \sim 85^{\circ}$ (Figure 11) as well as conform to the functional requirement and performance requirement. Mechanism D (Figure 9) is therefore referred to the production of the engineering prototype.

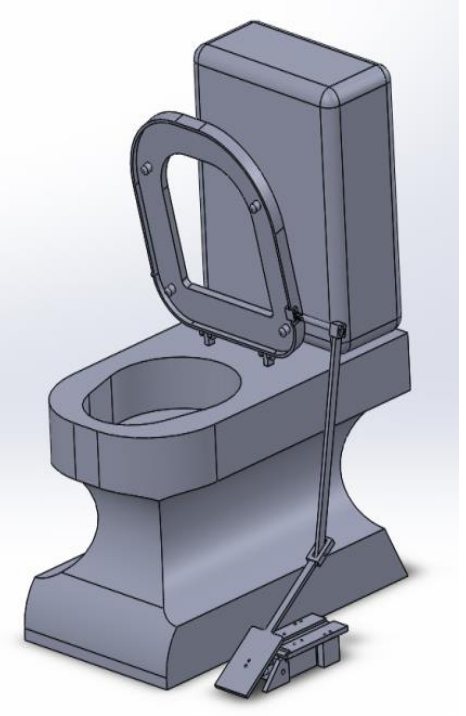

Figure 11. Mechanism D (seat lifting)
Table 3. Comparison of mechanism designs

\begin{tabular}{|l|c|c|}
\hline & Mechanism motion & Seat lifting range \\
\hline Mechanism A & Unusual (dead point) & Insufficient \\
\hline Mechanism B & Normal & Insufficient \\
\hline Mechanism C & Normal & Insufficient \\
\hline Mechanism D & Normal & Sufficient \\
\hline
\end{tabular}

\section{Seat lifting mechanism prototype production and experiment}

The major elements of the mechanism cover base, damper buffer device, structure fixing board, pedal, and seat lifting bar set, as following description.

\subsection{Base}

The base, Figure 12, presents 4 functions.

* To offer basic height for the pedal operation

* To fix the mechanism for not sliding

* To fix the damper buffer device

* To fix the pedal rotation axis

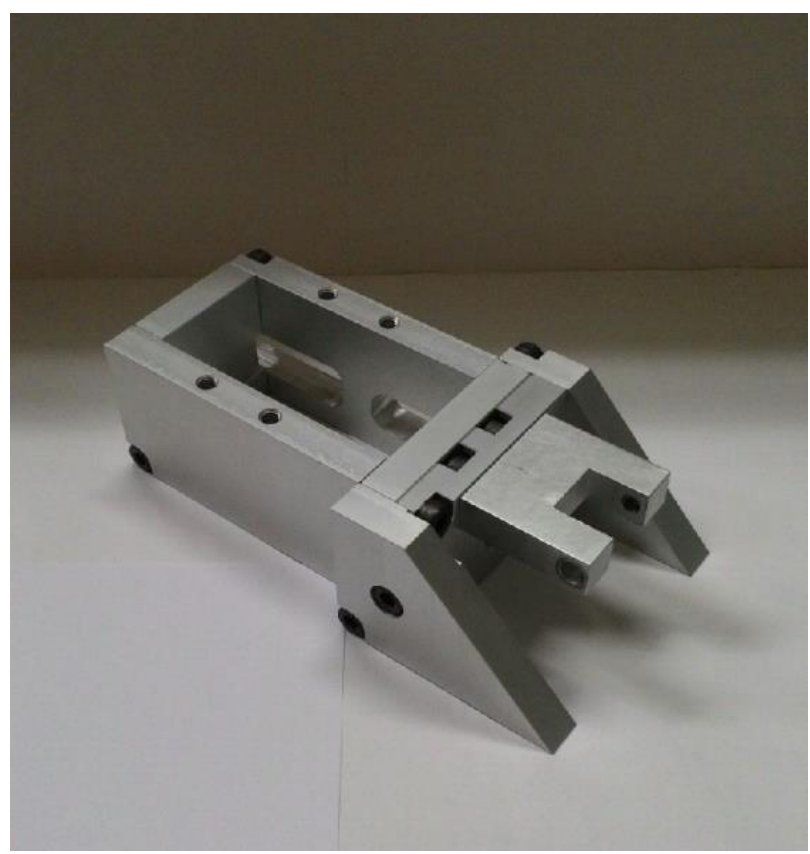

Figure 12. Base

\subsection{Damper buffer device}

The pen-shape spring cylinder, Figure 13, is used as the mechanism buffer for smoothly lifting and declining seats. The buffer range is adjustable according user needs (The red square in the figure is the adjuster). 


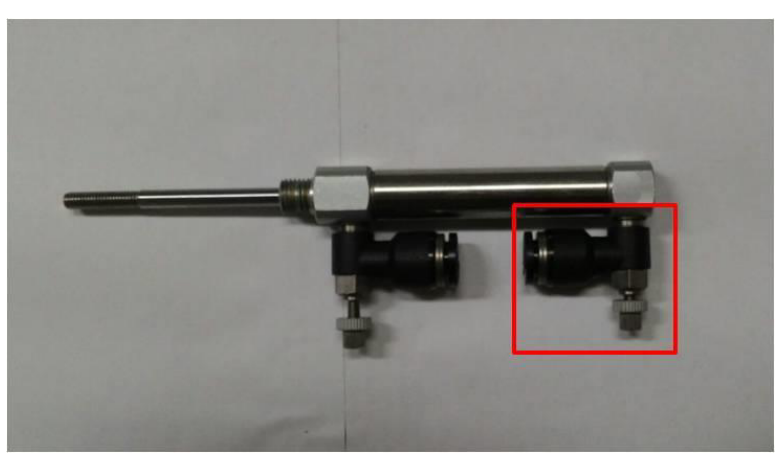

Figure 13. Damper buffer device

\subsection{Structure fixing board}

This board (Figure 14) is placed between the base and the pedal to provide the moving bars (for pedal and seat lifting bar set) with basic supporting force and to fix the pedal position.

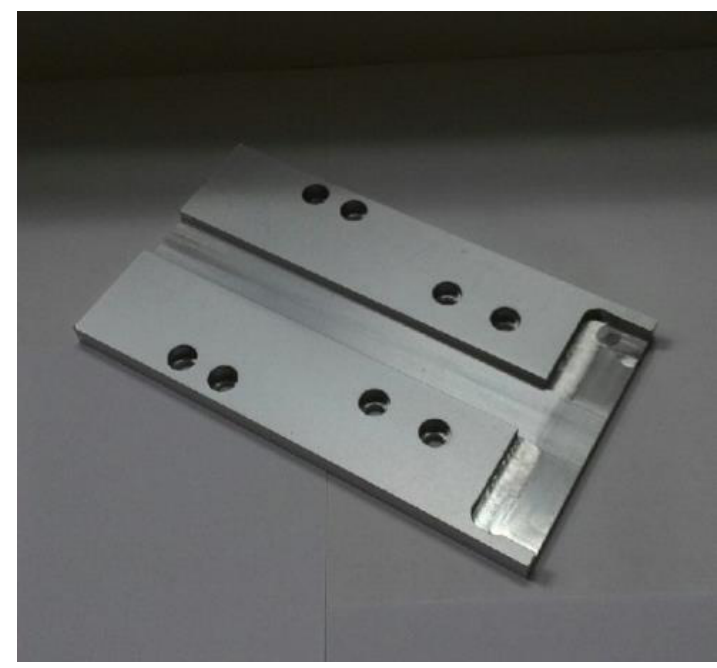

Figure 14. Structure fixing board

\subsection{Pedal}

The left of the pedal (Figure 15) is connected to the seat lifting bar set, and the base is the rotation center of the right in order to lift the seat lifting bar set to complete the seat lifting.

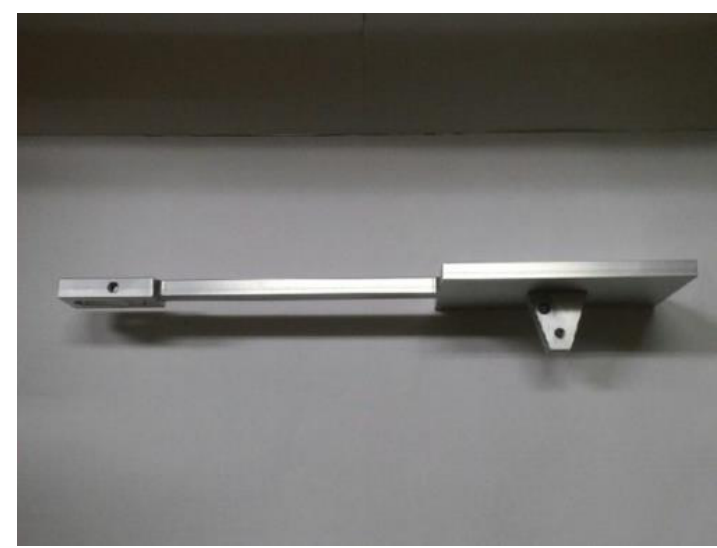

Figure 15. Pedal

\subsection{Seat lifting bar set}

Bar A (Figure 16) is connected with the pedal, responsible for delivering the upward force. Bar B (Figure 17) is clipped on the toilet seat, and the adjustable clip is designed for the application to toilet seats with different styles and thickness.

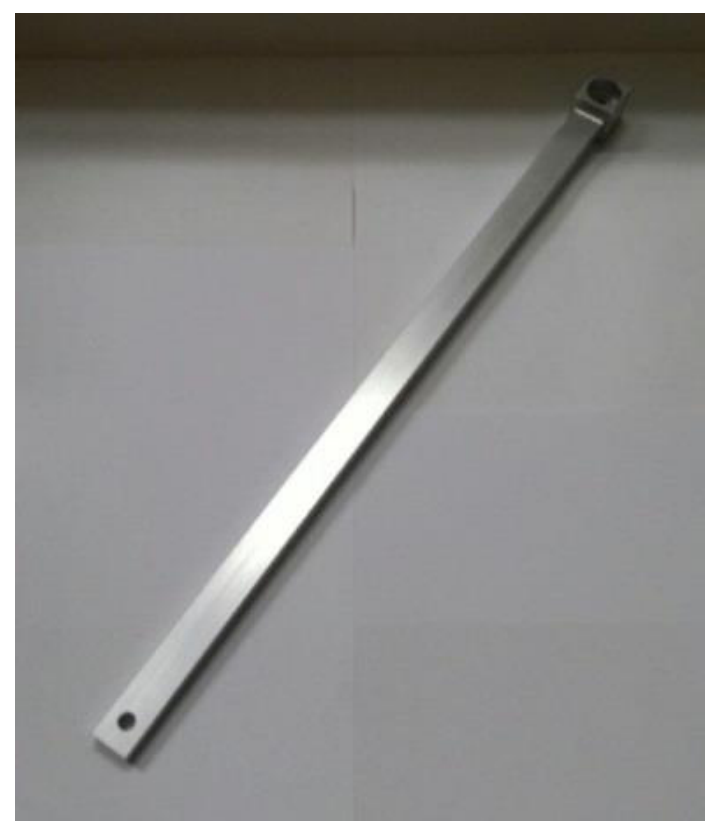

Figure 16. Seat lifting bar set A

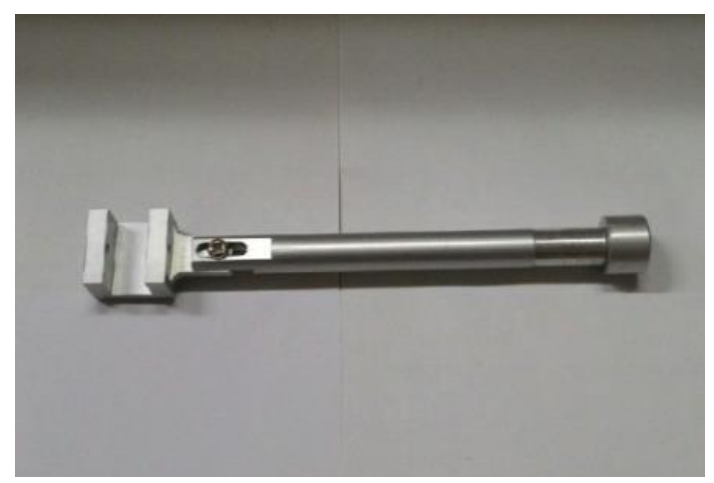

Figure 17. Seat lifting bar set $B$

The mechanism prototype is shown in Figure 18, and the real installation on a toilet is shown in Figure 19 and Figure 20. The preliminary test reveals the following situations.

\section{Uneasy buffer range adjustment}

The seat lifting speed is generally different from the declining speed that it requires a period of use time to adjust the damper buffer range.

\section{Abnormal sound of bars}

The collision of metal bars in the mechanism operation would induce little noise. Such a drawback is taken into consideration of future improvement. It is expected to include some plastic elements or add a rubber pad to the junction for the improvement. 


\section{Mechanism stability}

Figure 20 shows that the mechanism can easily shake in the stepping process because of uneven tile surface. The base bottom will be added a soft pad to slightly adjust the ground factor.

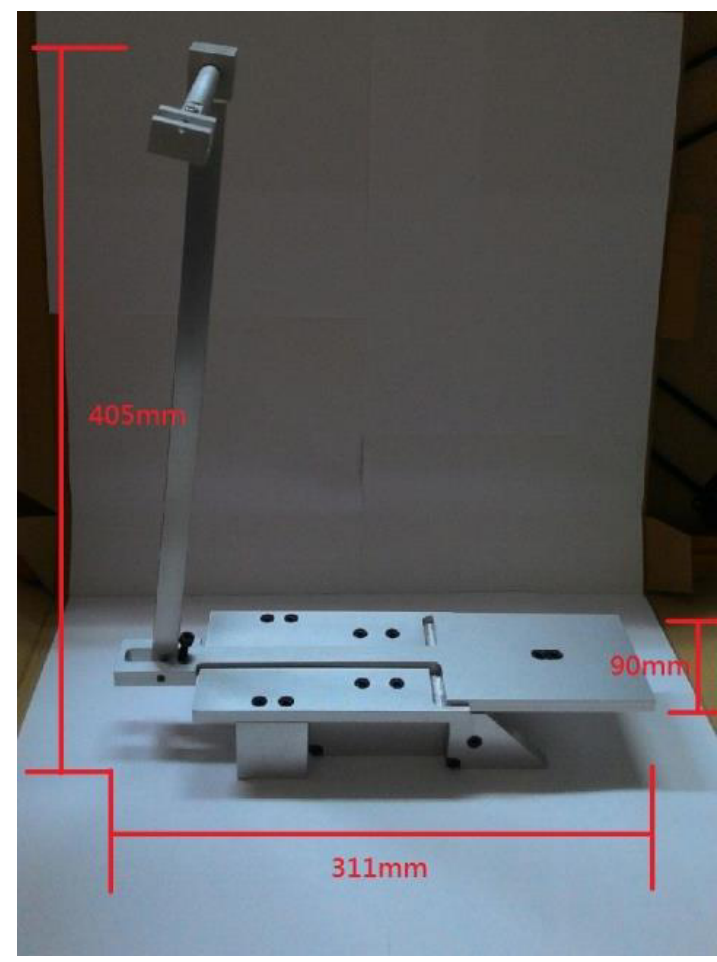

Figure 18. Complete mechanism assembly

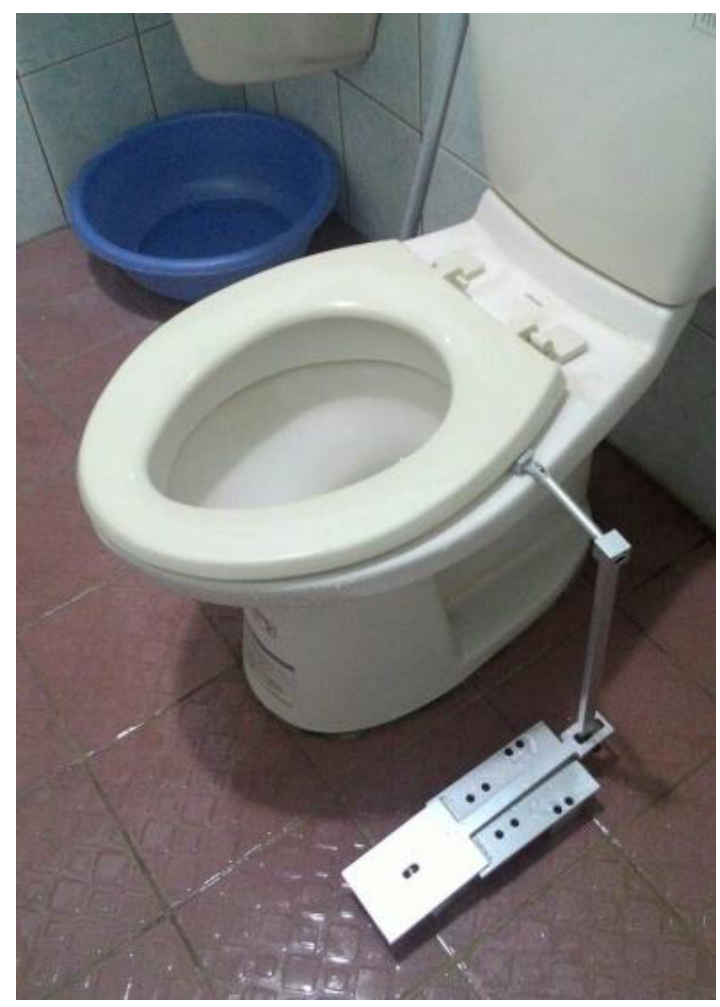

Figure 19. Real mechanism assembly

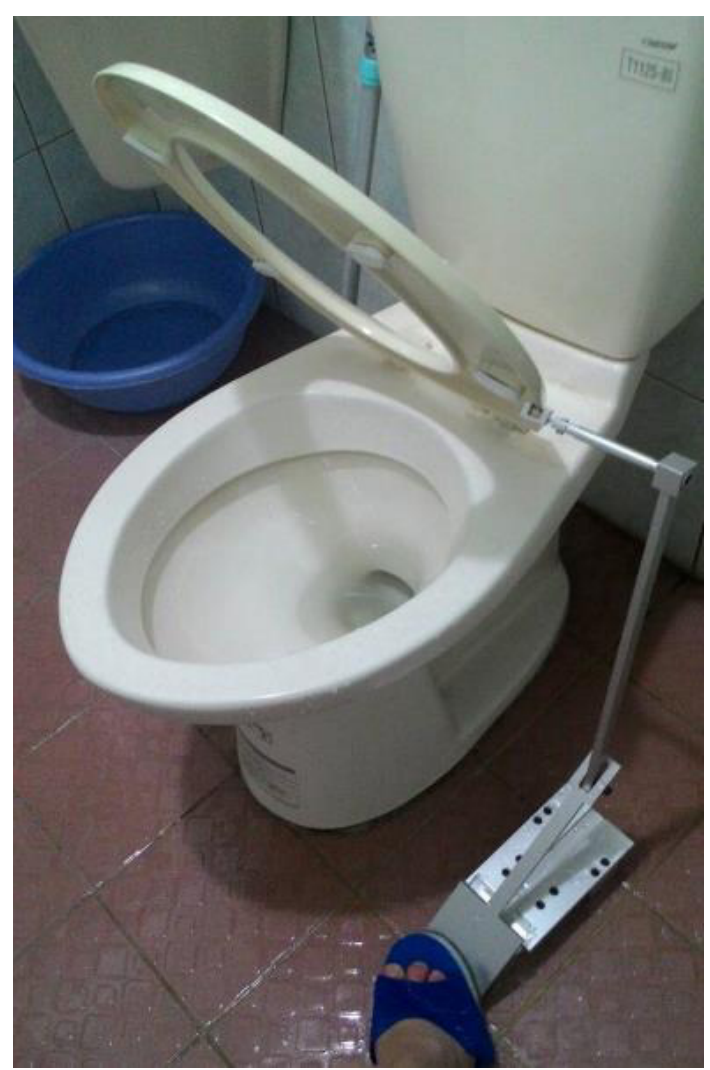

Figure 20. Seat lifting operation

\section{Conclusion}

Aiming at gender conflict in toilet, an engineering solution is proposed in this study to satisfy the basic requirement of humans through the mechanism design. With the suitable concept proposed from the aspect of requirement and the comparison among several mechanisms, the practicability of the engineering prototype is preliminarily proven. In addition to the improvement of the mechanism design, the public is invited for a longer time experience so as to objectively evaluate the mechanism efficiency for gender equality as well as to collect the shortcoming and the improvement direction of the mechanism design. It is expected to manifest the small problem-big trouble between genders in daily life. The mechanism design includes the requirement of humans that the performance is not the primary consideration. It therefore becomes a bridge to integrate research in different fields.

\section{Acknowledgement}

We are grateful for the project funding support of Ministry of Science and Technology (MOST 104-2629E-468-002) and would like to show our appreciation.

\section{References}

1. http://news.ltn.com.tw/news/focus/paper/736358, Last Browse Dates: 2016.03.28. 
2. http://www.twhealth.org.tw/index.php?option=com zoo\&task $=$ item\&item $\mathrm{id}=595 \&$ Itemid $=19, \quad$ Last Browse Dates: 2016.03.28.

3. http://blog.udn.com/ubhuang/5243877, Last Browse Dates: 2016.03.28.

4. http://www.hcg.com.tw/Product/Detail/147157492b25-46af-8527-34d6df9360b6, Last Browse Dates: 2016.03.28.

5. https://www.google.com.tw/search?q=\%E5\%9E\%83 $\%$ Е5\%9C $\%$ BE $\%$ E6\%A1\%B6\%Е6\%A9\%9F\%Е6\% $\mathrm{A} 7 \% 8 \mathrm{~B} \&$ source $=$ lnms \& tbm $=$ isch\&sa $=\mathrm{X} \& \mathrm{ved}=0 \mathrm{ah}$ UKEwitur6ly-LLAhUHIJQKHSHkA_AQ_AUICCg C\&biw $=1920 \&$ bih $=955$ \#imgrc $=$, $\quad$ Last Browse Dates: 2016.03.28.

6. Construction and Planning Agency, Ministry of the Interior, Taiwan, Public Buildings Hygienic Equipment Design Manual, 2010. (In Chinese)

7. http://www.hcg.com.tw/Bath, Last Browse Dates: 2016.03.28.

8. Footwear \& Recreation Technology Research Institute, A Data Analysis Report of Foot Shape Measurement of Adult Male in Taiwan (2011)

9. David H. Myszka, Machines \& Mechanisms: Applied Kinematic Analysis (4th Edition), Pearson, London, UK (2011) 